\title{
Patient Perspective Regarding Medical Services in 21st Century
}

\author{
Alexandrina Maria Pauceanu* \\ Higher Colleges of Technology, UAE \\ *Corresponding author: Alexandrina Maria Pauceanu, Higher Colleges of Technology, UAE. \\ To Cite This Article: Alexandrina Maria Pauceanu. Patient Perspective Regarding Medical Services in 21st Century. Am J Biomed Sci \& Res. \\ 2019 - 3(5). AJBSR.MS.ID.000718. DOI: 10.34297/AJBSR.2019.03.000718
}

Received: June 25, 2019 | Published: July 08, 2019

\section{Opinion}

To start, I would like to mention that this document is my opinion based on my personal experience from the previous years. It is not meant to accuse or denigrate anyone in anyway. It is meant to be a reflective document from a patient and business professional perspective. In the recent years, we have witnessed a boom of private medical practices. Do not get me wrong, this is a good thing from economic perspective; it is good from competition point of view as well. However, the question remains: what about us, the patients?

Fortunately, or unfortunately, in the last few years, I had to deal with doctors and hospitals much more than I was wishing or expecting. I have seen doctors who are just interested in money and they would ready to operate on "patient own reconnaissance" and full payment upfront until really professionals who had time to discuss with me the options, recommend the best minimum invasive method for me, explain the risks and provide guarantee for their work. In simple words, I have met doctors, not so much famous, who are consistent with their call and for them the priority is still the well-being of the patient, as well as famous doctors, and "well recommended" for whom the priority was only money and no responsibility for their actions.

So, what is the solution? Where do we, the patients, stand?

I would say that the selection on the market is ongoing. It is important for the patient to document well before taking any major decisions about any major procedure and to test the doctor's knowledge as well. The patients can as well-read reviews, ask for contact details of happy and unhappy patients in order to have a full image of what to expect. When your integrity and life is at stake, I believe us, the patients, are entitled to take all the necessary precautions and measures in order to select the best available medical care.
The next step is how do I find reliable sources to be informed? I would strongly advise to start from US Food and Drug Administration website (https://www.fda.gov/) where you can find comprehensive information about safe medical technology, procedures, side effects reported, etc. Next, there are several websites of ministries of health from each country from where you can complement the information. My next step would be medical professional blogs where there are many articles posted and where patients can address questions and get opinions from a variety of doctors.

Another issue mentioned often by my friends and first-hand experienced by myself as well is the lack of proper communication skills among the doctors. As a patient, I strongly believe that communication course should be "a must" in the medical school for atleast 1 year, because proper communication with patients increase the success rate of treatments as well the trust in the care provider.

Being so connected with technology nowadays and with access to such amount of information, as a patient, you do not have any excuse for not being informed or for not searching for information. It is also your responsibility to "do your homework" in advance (whenever is possible) and work in a partnership with the chosen medical provider in order to get the best possible output.

An old saying mentions that prevention is better than cure. With this thought in mind, I would like to recommend all the patients to make a priority out of their wellbeing because this body is the one who will take us through life. If we take good care of it inside and outside, we can have a smooth journey through life. 